\title{
EFEITO DA CONVECÇÃO FORÇADA NA MICRO E MACROESTRUTURA DE LINGOTES DE SILÍCIO GRAU METALÚRGICO OBTIDOS POR SOLIDIFICAÇÃO UNIDIRECIONAL*
}

\author{
Denir Paganini Nascimento ${ }^{1}$ \\ Marcelo de Aquino Martorano \\ João Batista Ferreira Neto ${ }^{2}$ \\ Moysés Leite de Lima ${ }^{3}$ \\ Tiago Ramos Ribeiro 2
}

\begin{abstract}
Resumo
O efeito da convecção forçada foi estudado na micro e macroestrutura de lingotes de silício grau metalúrgico obtidos pela solidificação unidirecional a partir da extração de calor por uma base refrigerada em contato com o fundo do cadinho com o banho líquido. Um disco sob rotação foi imerso no silício líquido para promover a convecção forçada. Em lingotes de $100 \mathrm{~mm}$, esta convecção aumenta de 8 para $80 \mathrm{~mm}$ o comprimento de uma região de grãos colunares claramente alinhados e livre de intermetálicos, indicando um aumento da macrossegregação. Um modelo de transferência de calor e massa indica que o aumento de transporte de soluto causado pela convecção forçada diminui $o$ super-resfriamento constitucional $e$, consequentemente, aumenta a estabilidade da interface sólido-líquido plana, sem células ou dendritas. A ausência de células e dendritas pode ter contribuído para a maior macrossegregação de impurezas observada sob efeito de convecção forçada.

Palavras-chave: Solidificação; Silício; Refino; Convecção.

\section{EFFECTS OF FORCED CONVECTION ON THE MICRO AND MACROSTRUCTURE OF METALLURGICAL GRADE INGOTS OBTAINED BY UNIDIRECTIONAL SOLIDIFICATION}

\section{Abstract}

The effects of forced convection were investigated on the micro and macrostructure of metallurgical grade silicon ingots obtained by unidirectional solidification imposed by a water-cooled base in contact with a crucible bottom containing the melt. A rotating disk was immersed into the silicon melt to force convection. In the resulting ingots, of 100$\mathrm{mm}$ height, convection increases from 8 to $80 \mathrm{~mm}$ the length of a region with clearly aligned columnar grains and free of intermetallic precipitates, indicating enhanced macrosegregation. A heat and mass transfer model indicates that the increase in solute transport caused by forced convection decreases the constitutional supercooling ahead of the solidification front and, accordingly, increases the stability of a planar solid-liquid interface, free from cells or dendrites. The absence of cells and dendrites may have contributed to increase macrosegregation with forced convection. Keywords: Solidification; Silicon; Refining; Convection.

1 Engenheiro Metalúrgico, Departamento de Engenharia Metalúrgica e de Materiais, Universidade de São Paulo, São Paulo, SP, Brasil.

2 Engenheiro Metalúrgico, Pesquisador, CTMM/LPM, Instituto de Pesquisas Tecnológicas do Estado de São Paulo, São Paulo, SP, Brasil.

3 Engenheiro de Materiais, Pesquisador, CTMM/LPM, Instituto de Pesquisas Tecnológicas do Estado de São Paulo, São Paulo, SP, Brasil. 


\section{INTRODUÇÃO}

A crescente demanda por silício para aplicações fotovoltaicas incentivou o desenvolvimento de rotas de processo alternativas mais econômicas para a produção de silício grau solar [1], [2]. Na rota metalúrgica o silício de grau metalúrgico, com pureza típica de $98,5 \%$, é refinado para atender os requisitos mais rigorosos necessários para ser classificado como silício grau solar. Em uma das etapas da rota metalúrgica, utiliza-se a solidificação unidirecional para retirar grande parte das impurezas metálicas [3], que são segregadas (macrossegregação) para a última parte do lingote a solidificar, deixando uma parte com silício mais puro. A intensidade da segregação está relacionada com o coeficiente de partição do soluto $\left(\boldsymbol{k}_{0}=C_{S} / C_{L}\right)$. Quanto menor for este coeficiente, maior a segregação do elemento correspondente. Com exceção do B, P e O, no caso do silício para a maioria das impurezas, $\boldsymbol{k}_{\mathbf{0}} \ll \mathbf{1}$, isso leva a uma intensa segregação de impurezas na interface sólido-líquido e, assim, torna possível a macrossegregação durante a solidificação controlada [4]. Com o efeito de macrossegregação as impurezas são concentradas na última região do lingote a solidificar, produzindo, assim, uma porção inicial com teores reduzidos de impurezas, ou seja, um material refinado com relação à composição inicial. Sabe-se que um aumento da convecção resulta em uma homogeneização da concentração de soluto no líquido durante a solidificação [5]. Também existem evidências de que a convecção pode eliminar as células ou dendritas alterando a morfologia da interface sólido-líquido para plana [6]. Desta forma, a convecção do líquido pode afetar tanto o transporte de soluto no líquido como a morfologia da interface sólido-líquido e estes dois efeitos podem alterar o nível de macrossegregação de impurezas. Apesar das indicações de que estes efeitos têm importância na macrossegregação, não há estudos para o caso da solidificação do silício. O entendimento destes efeitos no caso do silício poderia permitir a proposta de um processo de refino por solidificação direcional mais eficiente para a produção do silício de grau solar. O objetivo deste trabalho é estudar o efeito da convecção forçada na micro e macroestrutura de lingotes de silício de grau metalúrgico, como um primeiro passo para entender as consequências da convecção na macrossegregação. Foram realizados experimentos de solidificação unidirecional sem e com a utilização de convecção forçada no líquido e foi construído um modelo matemático de transporte de calor e massa para auxiliar no entendimento dos efeitos da convecção sobre o processo.

\section{MATERIAIS E MÉTODOS}

\subsection{Experimentos de solidificação direcional}

Foram realizados dois experimentos de solidificação direcional do silício de grau metalúrgico: um sem e outro com convecção forçada do líquido. Uma carga de 7,5kg de silício grau metalúrgico foi fundida em um forno a indução, aberto ao ambiente. Após fusão, o silício líquido foi transferido para um cadinho de grafita-argila posicionado em um forno preaquecido a $1600^{\circ} \mathrm{C}$ (Figura 1). Este forno apresenta duas partes: uma parte superior, onde estão localizados elementos resistivos, passagens para um funil de alimentação, poços de termopares e tubos de injeção de argônio; e uma parte inferior, onde está o cadinho de grafite-argila para o qual o silício líquido é transferido por meio de um funil. Este cadinho está apoiado sobre uma base de tijolos refratários com um furo passante que possibilita posicionar a coquilha de cobre refrigerada a água em contato com o fundo do cadinho. Esta coquilha promoverá a 
extração de calor que causará a solidificação, enquanto as laterais do cadinho são isoladas termicamente por refratários para resultar em uma extração de calor unidirecional. Durante todo o experimento foi injetado argônio continuamente para o interior do forno com o objetivo de diminuir a oxidação do silício. Dois termopares protegidos por um tubo de alumina foram inseridos no banho de silício líquido para registrar a evolução de temperatura durante todo o experimento em duas posições ao longo da altura (próximo à base e à superfície superior). Após a estabilização da temperatura do líquido, a coquilha de cobre foi posicionada em contato com o fundo do cadinho, iniciando a extração de calor unidirecional do conjunto (cadinho e silício). Os elementos resistivos permaneceram acionados durante todo o experimento fornecendo calor para a parte superior do banho. Os experimentos foram interrompidos quando a temperatura medida pelo termopar inserido no silício indicou $1000^{\circ} \mathrm{C}$, momento em que a solidificação já havia terminado.

No experimento em que a convecção forçada foi imposta ao silício líquido, um disco de grafite sob rotação constante de $360 \mathrm{rpm}$ foi imerso próximo à superfície superior do banho. Este disco estava acoplado a um eixo de grafite conectado a um motor elétrico. O disco foi mantido no banho até a interface de solidificação estar próxima à superfície superior do silício. Após o resfriamento, os lingotes foram seccionados longitudinalmente para análises de macro e microestruturas.

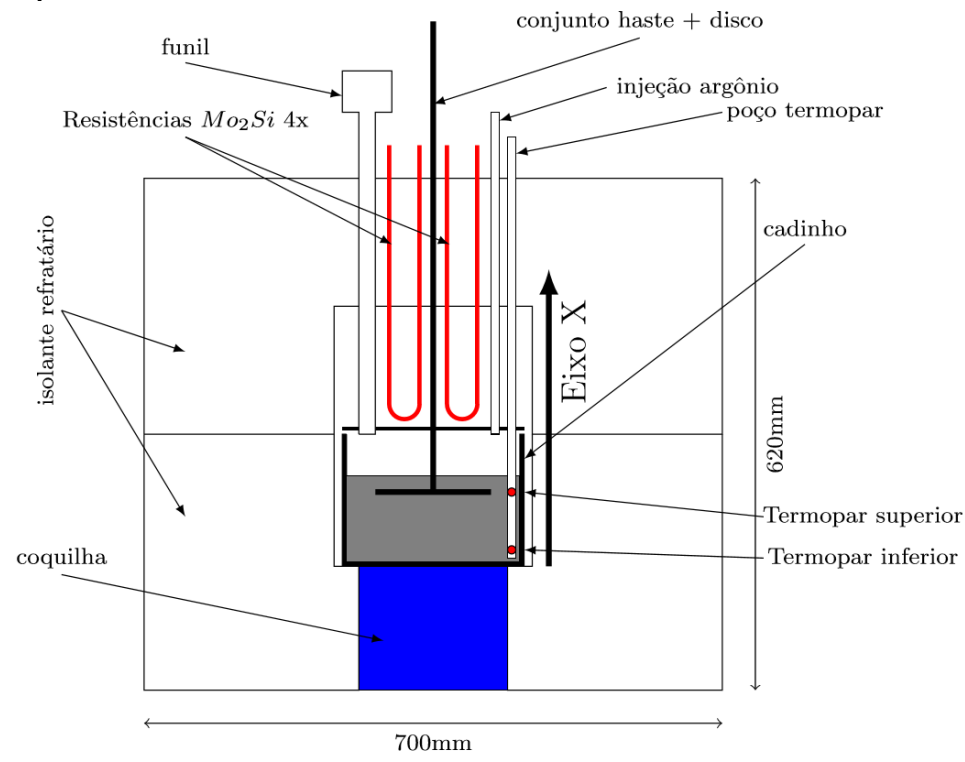

Figura 1 - Desenho esquemático do forno utilizado nos experimentos. O conjunto haste-disco de grafite foi utilizado apenas no experimento em que a convecção forçada foi imposta.

\subsection{Modelo matemático da solidificação direcional do lingote}

A transferência de calor durante a solidificação unidirecional do lingote foi modelada utilizando-se o método da entalpia, a partir da equação abaixo [7]:

$$
\frac{\partial H}{\partial t}=\frac{\partial}{\partial x}\left(K \frac{\partial T}{\partial x}\right)
$$

onde, $H$ é a entalpia, $K$ a condutividade térmica efetiva, $T$ a temperatura, $t$ o tempo e $x$ a distância em relação à base do cadinho cilíndrico, ao longo do seu eixo longitudinal. A condutividade térmica efetiva $(K)$ foi considerada constante no sólido e no líquido. Para o sólido, foi assumida à condutividade térmica medida a $1400^{\circ} \mathrm{C}$, enquanto no líquido foi considerada igual à condutividade térmica medida a $1450^{\circ} \mathrm{C}$, multiplicada por 5 para considerar de forma aproximada o efeito da convecção 
forçada. Todas as propriedades utilizadas nas simulações estão apresentadas na Tabela 1. Como condições de contorno, utilizaram-se as duas curvas de resfriamento medidas pelos termopares inseridos no silício. A Eq. (1) foi solucionada pelo método dos volumes finitos, na sua formulação explícita.

Tabela 1 - Propriedades da liga silício-ferro [8,9]

\begin{tabular}{|l|c|l|c|c|c|}
\hline Propriedade & Valor & Propriedade & Valor & Propriedade & Valor \\
\hline $\mathrm{m}\left(\mathrm{K} \cdot \%^{-1}\right)$ & $-1,1$ & $\mathrm{k}$ & $8,00 \times 10^{-6}$ & $\mathrm{C}_{\mathrm{ps}}\left(\mathrm{J} \cdot \mathrm{g}^{-1} \cdot \mathrm{K}^{-1}\right)$ & 1,05 \\
\hline $\mathrm{D}_{\mathrm{Fe}}\left(\mathrm{m}^{2} \cdot \mathrm{s}^{-1}\right)$ & $1,8 \times 10^{-8}$ & $\mathrm{Ks}\left(\mathrm{W} \cdot \mathrm{m}^{-1} \cdot \mathrm{K}^{-1}\right)$ & 28 & $\mathrm{C}_{\mathrm{pL}}\left(\mathrm{J} \cdot \mathrm{g}^{-1} \cdot \mathrm{K}^{-1}\right)$ & 0,968 \\
\hline $\mathrm{C}_{0}(\%)$ & 0,1368 & $\mathrm{~K} \mathrm{~L}\left(\mathrm{~W} \cdot \mathrm{m}^{-1} \cdot \mathrm{K}^{-1}\right)$ & 58,5 & $\Delta \mathrm{H}_{\mathrm{s}}\left(\mathrm{J} \cdot \mathrm{g}^{-1}\right)$ & 1803 \\
\hline
\end{tabular}

\section{RESULTADOS E DISCUSSÃO}

\subsection{Micro e macroestruturas dos lingotes}

A macroestrutura do lingote de silício do experimento sem convecção forçada mostra, em sua maior parte, uma estrutura de grãos aproximadamente colunares de contornos irregulares e serrilhados, sem uma orientação comum evidente (Figura 2(a)). Em uma camada de aproximadamente $8 \mathrm{~mm}$ junto à base, e na região próxima à parede lateral do cadinho, nota-se a presença de grãos colunares de contornos regulares e com orientação comum, aproximadamente paralela à direção de extração de calor. Nessas regiões, acredita-se que a interface sólido-líquido tenha a morfologia planar (ausência de células e dendritas), onde o aparecimento de precipitados seria dificultado. A análise da microestrutrura não mostrou a presença de compostos intermetálicos na região da base até $8 \mathrm{~mm}$ de altura (Figura 2(c)). A partir de $8 \mathrm{~mm}$ a partir da base, a análise da microestrutura mostrou a presença de precipitados intermetálicos, coincidindo com o final da região de grãos colunares orientados, conforme pode ser visto na Figura 2(b). A presença de precipitados intermetálicos indica uma região com maior concentração de impurezas e também pode indicar a existência de uma estrutura celular ou dendrítica, ou seja, a ausência de uma interface sólido-líquido plana [9].
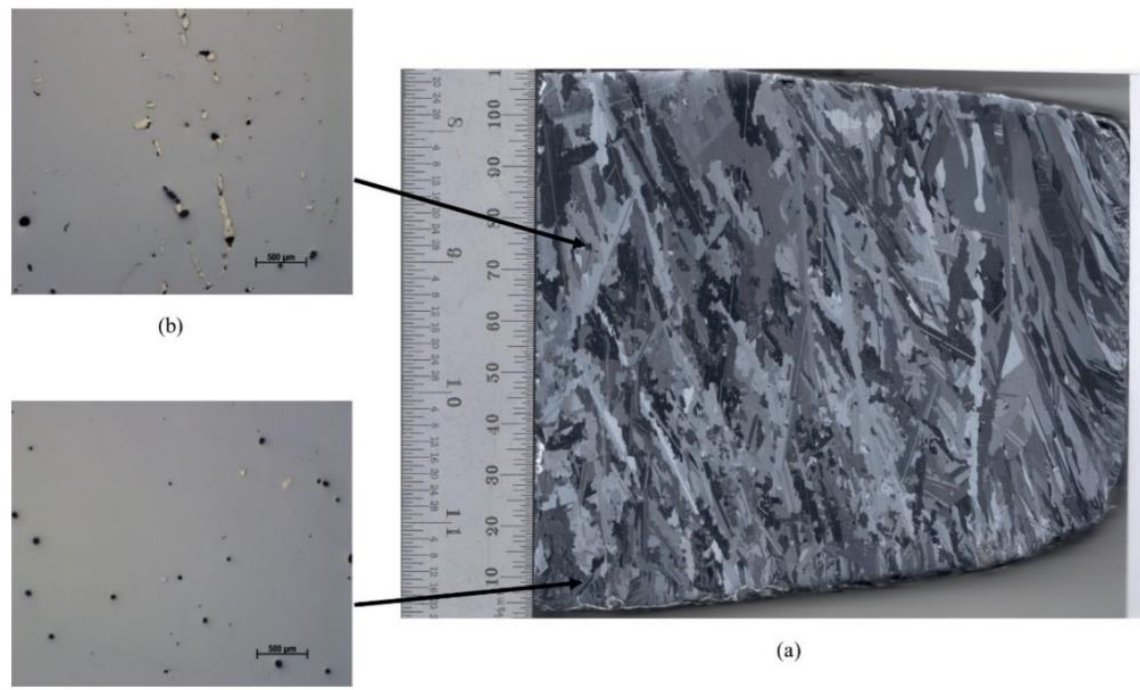

(a)

Figura 2 - Experimento sem convecção forçada: (a) macrografia do lingote; (b) micrografia à 75mm da base e (c) micrografia à $8 \mathrm{~mm}$ da base. 
Na Figura 3(a), a macroestrutura do lingote de silício do experimento com convecção forçada mostra, em sua maior parte, grãos colunares com contornos bem definidos e orientados aproximadamente na direção de extração de calor, até uma distância de aproximadamente $80 \mathrm{~mm}$ em relação à base do lingote. Em toda esta região, não foram observados intermetálicos na microestrutura, indicando um teor reduzido de impurezas. Novamente, acredita-se que a ausência de precipitados indica que a interface sólido-líquido apresentava uma morfologia planar nesta região. A partir de $80 \mathrm{~mm}$ da base, são observados intermetálicos (Figura 3(b)) e os grãos apresentam contornos irregulares e serrilhados com orientação aleatória.

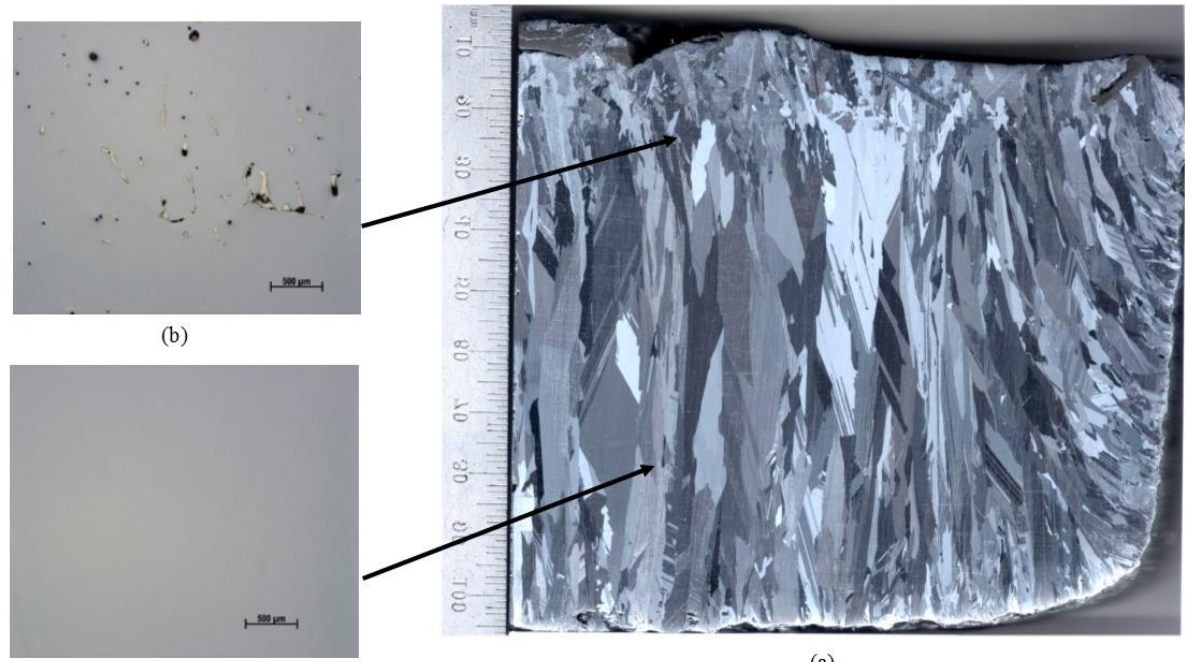

(c)

(a)

Figura 3 - Experimento com convecção forçada: (a) macrografia do lingote; (b) micrografia à 25mm da base e (c) micrografia à $80 \mathrm{~mm}$ da base.

\subsection{Análise do transporte de calor e massa na solidificação direcional}

A posição da interface sólido-líquido, a sua velocidade e o gradiente de temperatura (Figura4) no líquido junto a esta interface foram calculados pelo modelo matemático implementado no presente trabalhoErro! Fonte de referência não encontrada., para os casos sem e com a convecção forçada. As curvas de posição da interface em função do tempo mostram que a interface no experimento com convecção forçada está à frente da interface do experimento sem convecção forçada para um dado instante de tempo durante a maior parte da solidificação do lingote (Figura 4(a)). Consistentemente, nota-se na Figura 4(b) que as velocidades permanecem em valores relativamente constantes, sem grandes variações, durante a maior parte do tempo. No entanto, a velocidade da interface no experimento com convecção atinge valores cerca de $50 \%$ maiores que no caso sem convecção. O gradiente térmico no líquido, próximo à interface, também apresenta valores constantes durante a maior parte do experimento. Na presença de convecção, este gradiente é aproximadamente 500 vezes menor (Figura 4(c)), algo esperado pois a convecção forçada tende a homogeneizar a temperatura do banho. 


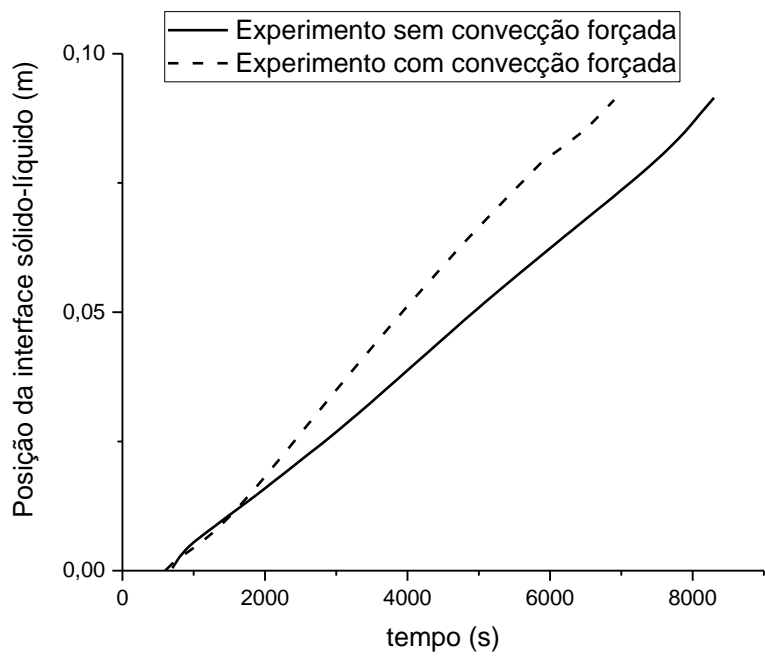

(a)

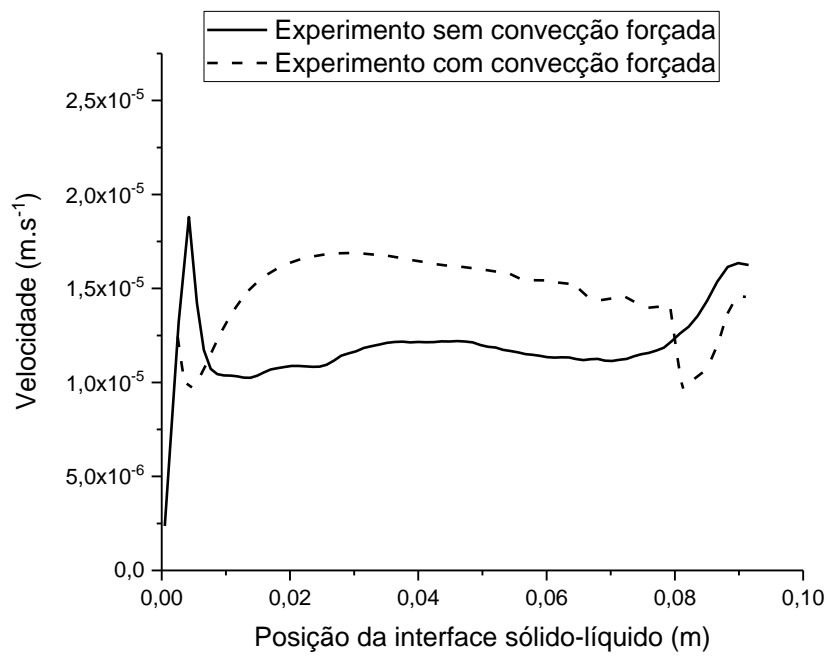

(b)

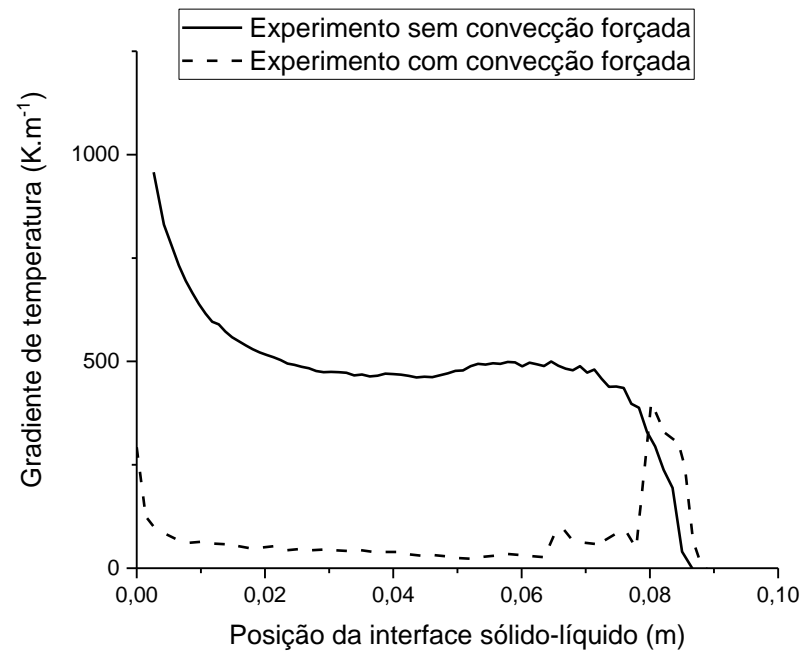

(c)

Figura 4 - Resultados obtidos com o modelo matemático de transporte de calor: (a) posição da interface em função do tempo; (b) velocidade da interface e (c) gradiente de temperatura no líquido à frente da interface em função da sua posição. 
Os resultados do modelo de transporte de calor foram utilizados para realizar cálculos relativos ao super-resfriamento constitucional existente à frente da interface sólidolíquido. Estes cálculos têm o objetivo de verificar se as condições à frente da interface de solidificação permitem a existência de uma interface plana, o que aumentaria a macrossegregação de impurezas e, consequentemente, a purificação. Nesta análise foi utilizado o critério do super-resfriamento constitucional modificado por Hurle [6] para incluir o efeito da convecção no líquido. Este autor definiu junto à interface uma camada de líquido estagnada, no interior da qual o soluto é transportado apenas por difusão, mas externamente está completamente homogêneo com relação à concentração de soluto. Segundo este modelo, o super-resfriamento constitucional $\left(S_{\text {conv }}\right)$, que representa a diferença entre o gradiente de temperatura liquidus e 0 gradiente de temperatura real, pode ser calculado por:

$$
S_{\text {conv }}=-\frac{m V C_{L \infty}(1-k)}{D\left[k+(1-k) e^{-\Delta}\right]}-G_{L}
$$

onde, $m$ é o coeficiente angular da linha liquidus, $V$ a velocidade da interface obtida a partir da Figura 4(b), $C_{L \infty}$ é a concentração no interior do líquido completamente misturado, fora da camada estagnada, $k$ é o coeficiente de partição, $D$ o coeficiente de difusão, $G_{L}$ o gradiente térmico no líquido à frente da interface, obtido a partir da Figura 4(c). A concentração no líquido misturado, $C_{L \infty}$, foi calculada pela equação de Scheil apresentada abaixo, como proposto por Pfann [10] para este tipo de modelo:

$$
C_{L \infty}=C_{0} f_{l}^{(k-1)}(3)
$$

onde $C_{0}$ é a concentração inicial de impureza no líquido e $f_{l}$ a fração de líquido total no sistema. O parâmetro convectivo-difusivo, $\Delta$, que está definido abaixo, indica a importância da convecção no líquido para o transporte de soluto em comparação com o transporte por difusão:

$$
\Delta=\frac{V \delta}{D}
$$

onde $\delta$ é a espessura da camada estagnada. Quando $S_{c o n v}<0$, não há superresfriamento constitucional e, portanto, existem condições para que uma interface sólido-líquido plana seja estável. Por outro lado, quando $S_{c o n v}>0$, há superresfriamento constitucional e, por isso, uma interface com células ou dendritas é mais provável. Quanto maior for a convecção no líquido, menor será a espessura $\delta$ e, segundo as equações (2) e (4), o valor de $\Delta$ diminui, resultando em um decréscimo em $S_{\text {conv }}$, tornando as condições mais propícias ao aparecimento da interface plana. Desta forma, nota-se que a convecção forçada deve favorecer a estabilização da interface plana durante a solidificação do silício, favorecendo também o aumento da macrossegregação de soluto e a purificação.

Quando não há convecção no líquido, $\delta \rightarrow \infty$, correspondendo a $\Delta \rightarrow \infty$ e $C_{L \infty} \rightarrow C_{0}$, ou seja, o líquido completamente misturado terá a composição do líquido inicial, já que torna-se semi-infinito. Neste caso, o super-resfriamento constitucional dado pela equação (2) torna-se:

$$
S_{\text {dif }}=-\frac{m V C_{0}(1-k)}{D k}-G_{L}
$$

Este parâmetro, $S_{\text {dif }}$, coincide com o critério do super-resfriamento constitucional clássico, originalmente proposto por Tiller et al. [11], aplicado a um sistema onde a solidificação atingiu o estado-estacionário sem a presença de convecção no líquido. Quando não há convecção e $S_{d i f}>0$, não há possibilidade para a existência da interface plana. Logo, quando a interface é plana e $S_{\text {dif }}>0$, pode-se concluir que deve existir algum tipo de convecção que está estabilizando este tipo de interface. Neste caso, fazendo-se $S_{\text {conv }}=0$, seria obtida a máxima espessura de camada 
estagnada possível $\left(\delta_{\max }\right)$, ou seja, o menor nível de convecção necessário para manter a estabilidade da interface plana, resultando em:

$$
\delta_{\text {max }}=-\frac{D}{V} \ln \left(-\frac{m V C_{L \infty}}{G_{L} D}-\frac{k}{1-k}\right)
$$

Quanto menor o valor de $\delta_{\max }$, maior seria o nível de convecção necessário para manter a interface plana estável. Por outro lado, quando $\delta \rightarrow 0$, tem-se o efeito do máximo nível de convecção possível no sistema. Para este valor, a equação (2) indicaria o mínimo nível de super-resfriamento constitucional $\left(S_{\min }\right)$ possível de ser atingido com a presença da convecção, calculado como:

$$
S_{\min }=-\frac{m V C_{L \infty}(1-k)}{D}-G_{L}(7)
$$

Pode-se dizer que quando $S_{\min }>0$, nenhum tipo de convecção, por mais vigorosa que seja, estabilizaria a interface sólido-líquido plana. Os parâmetros $S_{\text {conv }}, S_{d i f}, S_{\text {min }}$ e $\delta_{\max }$ foram calculados utilizando as propriedades de uma liga binária Si-Fe contendo 1368 ppm de Fe (Tabela 1) para representar o silício grau metalúrgico. No cálculo destes parâmetros, foram utilizados os valores de $G_{L}$ e $V$ obtidos pelo modelo de transferência de calor e apresentados na Figura 4.

No caso do experimento sem convecção forçada, a Figura 5(a) mostra os parâmetros $S_{d i f}, S_{c o n v}$ e $\delta_{\text {max }}$ para cada posição da interface sólido-líquido, calculada pelo modelo de transferência de calor. Como $S_{\text {dif }}>0$ para qualquer posição, conclui-se que uma interface sólido-líquido plana não tem condições de ser estável na ausência de convecção. Porém, como apresentado na Figura 2, a interface plana parece existir até uma distância de aproximadamente $8 \mathrm{~mm}$ em relação à base do lingote, o que poderia indicar uma possível estabilização causada pela convecção natural do líquido. $O$ parâmetro $\delta_{\max }$ também está mostrado na Figura 2, indicando qual seria o nível de convecção necessário para sempre manter a interface plana estável durante toda a solidificação. Nota-se que, para estabilidade até a posição de $8 \mathrm{~mm}$ (espessura identificada na Figura 2(a)), tem-se $\delta_{\max }=7,86 \mathrm{~mm}$. Este valor indica um nível de convecção relativamente reduzido, sendo da ordem de grandeza dos valores obtidos por Martorano et al. (4 mm) [9], Rouzaud et al. $(7,125 \mathrm{~mm})$ [12] e Ren et al. $(6 \mathrm{~mm})$ [13]. Este valor é típico da presença da convecção natural. Finalmente, o parâmetro $S_{c o n v}$ foi calculado utilizando-se $\delta=7,86 \mathrm{~mm}$, mostrando condições de estabilidade $\left(S_{c o n v}<0\right)$ até a posição de $8 \mathrm{~mm}$, como esperado para o valor de $\delta$ utilizado. 


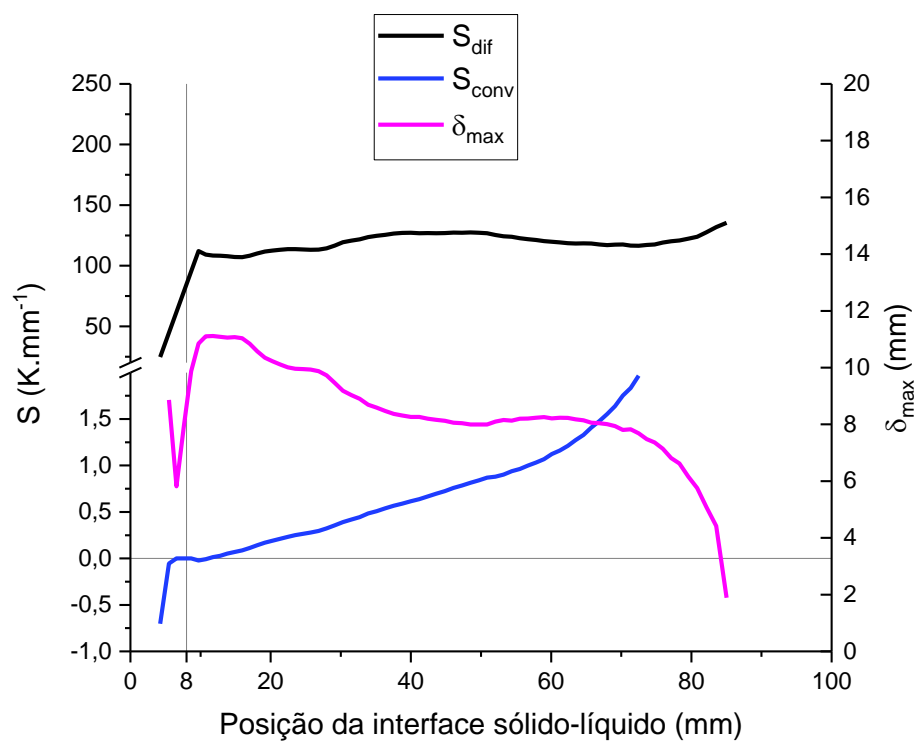

(a)

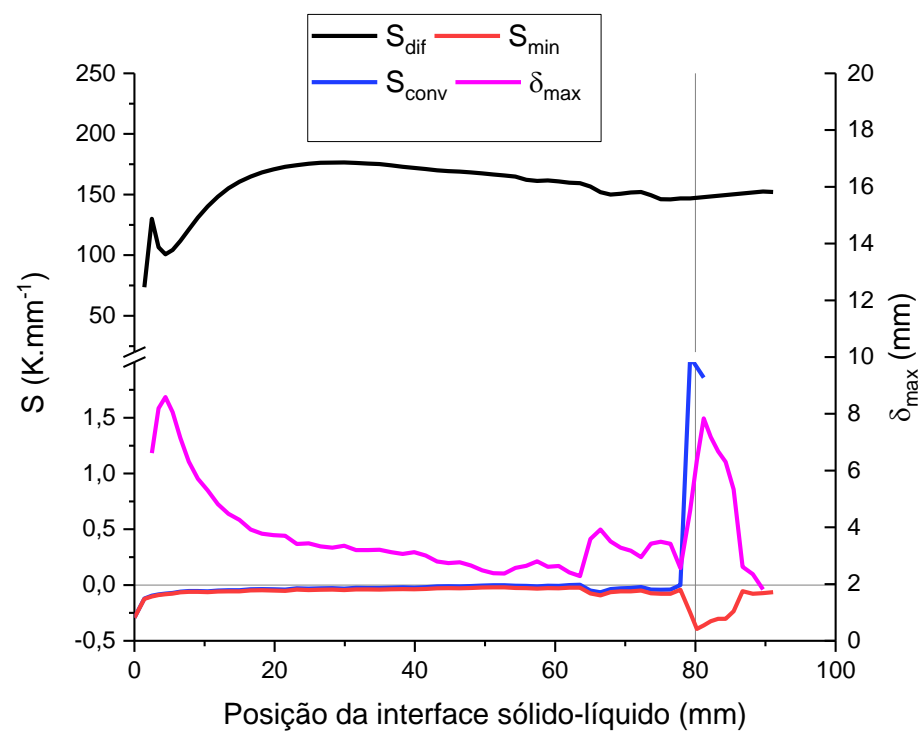

(b)

Figura 5 - Valores de $S_{\text {conv }}, S_{\text {dif }}, S_{\min }$ e $\delta_{\max }$ calculados em função da posição da interface sólido-líquido identificada pelo modelo matemático de transferência de calor para o experimento (a) sem e (b) com convecção forçada.

A Figura 5(b) ilustra os cálculos para o experimento com a convecção forçada introduzida pelo disco sob rotação. Novamente, como $S_{\text {dif }}>0$ durante toda a solidificação, pode-se concluir que na ausência de convecção não há condições para a estabilidade da interface plana. Entretanto, a Figura 3(a) mostra uma possibilidade de existência da interface solido-líquido plana até aproximadamente $80 \mathrm{~mm}$ em relação à base do cadinho. Uma possível explicação seria a estabilização pela convecção forçada. Logo, o parâmetro $\delta_{\max }$ foi calculado para indicar o mínimo nível de convecção necessário para manter a interface plana estável até $80 \mathrm{~mm}$. Notam-se valores na faixa entre 2 e $8 \mathrm{~mm}$. O valor $\delta=2,57 \mathrm{~mm}(\Delta=2)$ garante $S_{\text {conv }}<0$ até 80 $\mathrm{mm}$, como observado na macroestrutura apresentada na Figura 5(b). Este menor valor de $\delta$ indica um maior nível de convecção quando comparado ao experimento sem a convecção forçada $(\delta=7,86 \mathrm{~mm})$, estando consistente com a mudança da convecção 
natural para a convecção forçada. Os valores de $S_{\text {min }}$ sempre negativos mostram que seria possível manter a estabilidade da interface plana por todo o lingote desde que uma convecção forçada suficientemente vigorosa fosse introduzida.

As curvas do critério clássico do super-resfriamento constitucional, dado por $S_{d i f}$, foram comparadas na Figura 6 para os experimentos com e sem a convecção forçada. Este critério indica as condições para a estabilidade da interface plana para a velocidade de solidificação e gradiente térmico calculados pelo modelo matemático. Neste parâmetro, desconsidera-se efeitos de convecção no transporte de soluto no líquido. Observa-se que $S_{d i f}$ é maior para o experimento com a convecção forçada, mostrando que o aumento da velocidade de solidificação e a diminuição do gradiente de temperatura causados pela convecção forçada resultaram em condições mais favoráveis para a presença de células e dendritas, ou seja, ausência da interface plana, ao contrário do que sugerem as macroestruturas dos lingotes. No entanto, na Figura 5, o parâmetro $S_{c o n v}$, onde o efeito da convecção no transporte de soluto é considerado, mostrou que a convecção forçada resulta em condições de maior estabilidade para interface plana. Desta forma, conclui-se que a maior estabilidade da interface plana observada nos experimentos com a convecção forçada é resultado principalmente do maior transporte de soluto no líquido, diminuindo o gradiente de temperatura liquidus e, consequentemente, diminuindo 0 super-resfriamento constitucional.

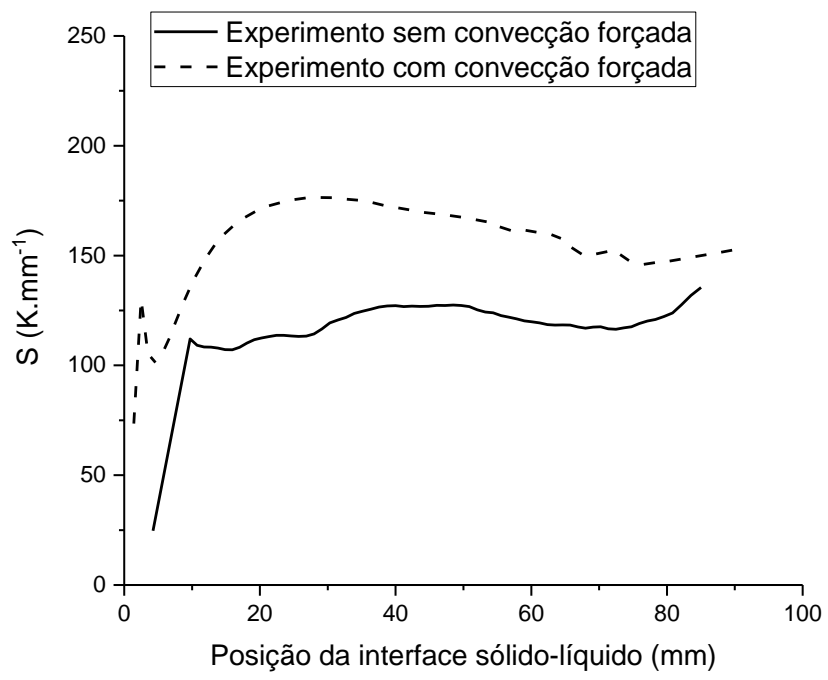

Figura 6 - Valores de $S_{\text {dif }}$ calculados em função da posição da interface sólido-líquido identificada pelo modelo matemático de transferência de calor para os experimentos sem e com convecção forçada.

\section{CONCLUSÃO}

Foram realizados experimentos de solidificação direcional de silício grau metalúrgico com e sem convecção forçada do líquido. Nota-se que na ausência da convecção forçada, obtém-se um lingote com uma camada de aproximadamente $8 \mathrm{~mm}$ de sólido isenta de intermetálicos e contendo grãos colunares claramente alinhados, indicando a presença de uma interface sólido-líquido plana. Nas mesmas condições de extração de calor, a introdução da convecção forçada no líquido a partir de um disco sob rotação aumentou a camada de sólido isento de intermetálicos de 8 para $80 \mathrm{~mm}$, mostrando que este tipo de convecção aumenta a macrossegregação de impurezas e 
também, aparentemente, a estabilidade da interface sólido-líquido plana. Foi implementado um modelo de transporte de calor numérico acoplado ao critério do super-resfriamento constitucional modificado para considerar o efeito de convecção no transporte de soluto. Este modelo indica que o maior transporte de soluto causado pela convecção forçada pode explicar a maior estabilidade da interface plana nas condições dos experimentos do presente trabalho.

\section{Agradecimentos}

Agradecemos à CAPES e à FIPT pelas bolsas concedidas a um dos autores (D.P.N.) e à bolsa concedida pelo CNPq, processo 311206/2014-0.

\section{Referências}

[1] E. Ovrelid, M. Juel, M. Bellmann e B. Tuffour, "Refining of solar grade silicon by directional solidification," em Silicon for the Chemical and Solar Industry IX, Oslo, Noruega, 2008.

[2] D. Lynch, "Winning the global race for solar silicon," JOM, pp. 41-48, 2009.

[3] P. Woditsch e W. Koch, "Solar grade silicon feedstock supply for PV industry," SOLAR ENERGY MATERIALS AND SOLAR CELLS, pp. 11-26, 2002.

[4] J. P. Garandet, "New Determinations of Diffusion Coefficients for Various Dopants in Liquid Silicon," International Journal of Thermophysics, pp. 12851303, 2007.

[5] J. A. Burton, R. C. Prim e W. P. Slichter, "The distribution of solute in crystals grown from the melt," JOURNAL OF CHEMICAL PHYSICS, pp. 1987-1991, 1953.

[6] D. Hurle, "Constitutional supercooling during crystal growth from stirred melts-I," Solid-state eletronics, pp. 37-44, 1961.

[7] V. Voller e M. Cross, "Accurate solutions of moving boundary problems using the enthalpy method," International journal fo heat and mass transfer, pp. 545556, 1981.

[8] K. C. Mills e L. Courtney, "Thermophysical Properties of Silicon," ISIJ International, vol. 40, pp. S130-S138, 2000.

[9] M. Martorano, J. Ferreira Neto, T. Oliveira e T. Tsubaki, "Macrosegregation of Impurities in Directionally Solidified Silicon," METALLURGICAL AND MATERIALS TRANSACTIONS A, pp. 1870-1886, 2011.

[10] W. Pfann, "Principles of Zone Melting," Journal of Metals, pp. 747-753, 1952.

[11] W. A. Tiller, K. A. Jackson, J. W. Rutter e B. e Chalmers, "The redistribution of solute atoms during solidification of metals," Acta Mettalurgica, pp. 428-437, 1953.

[12] A. Rouzaud, D. Camel e J. J. Favier, "A comparative study of thermal and thermosolutal convective effects in vertical bridgman crystal growth," Journal of Crystal Growth, pp. 149-166, 1985.

[13] S. Ren, P. Li, D. Jiang, S. Shi, J. Li, S. Wen e Y. Tan, "Removal of Cu, Mn and $\mathrm{Na}$ in multicrystalline silicon by directional solidification under low vacuum condition," Vacuum, pp. 108-112, 2015. 